\title{
Investigations of the Montmorillonite and Aluminium Trihydrate Addition Effects on the Ignitability and Thermal Stability of Asphalt
}

\author{
Kai Zhu, Ke Wu, Bin Wu, and Zhiyi Huang \\ College of Civil and Architecture Engineering, Zhejiang University, Hangzhou 310027, China \\ Correspondence should be addressed to Ke Wu; wuke@zju.edu.cn
}

Received 4 June 2014; Accepted 14 July 2014; Published 6 August 2014

Academic Editor: Ying Zhou

Copyright @ 2014 Kai Zhu et al. This is an open access article distributed under the Creative Commons Attribution License, which permits unrestricted use, distribution, and reproduction in any medium, provided the original work is properly cited.

By means of limiting oxygen index (LOI), cone calorimeter, and TG-DSC tests, this paper investigated the effect of unmodified montmorillonite (MMT), organically modified montmorillonite (OMMT), and aluminium trihydrate (ATH) additions on the flame retardancy for asphalt combustion. Experimental results showed that adding a small amount of montmorillonite did not significantly increase the oxygen index of the asphalt but reduced the heat release rate during asphalt combustion. TGA tests had indicated that the montmorillonite (MMT and OMMT) could suppress the release of flammable volatiles and form more asphaltenes, which hence postponed the burnout time of asphalt. Furthermore, the combination of montmorillonite (MMT and OMMT) and ATH had yielded a synergistic effect, which had further reduced the heat release rate and also increased the oxygen index of asphalt. In particular, after further addition of OMMT, the barrier layer showed less crack, leading to a significant decrease in the heat release rate as compared to the adding of ATH alone.

\section{Introduction}

Asphalt is a viscoelastic liquid or semisolid with remark rheology properties and impermeability. It has been widely used as binder and matrix precursor in road pavement, water proofing, composite synthesis, and so forth. However, the asphalt materials are generally flammable, which would be decomposed at a relatively low temperature $\left(\mathrm{ca} .300^{\circ} \mathrm{C}\right)$ [1] During asphalt combustion (especially in the case of tunnel fire) [2], the generated heat and toxic fumes [3] will promote the spread of fire and seriously endanger any personnel within the affected areas. As such, studies on the flame retardancy of asphalt materials become highly desirable.

Due to the nontoxic and smoke suppression properties, metal hydroxides, such as magnesium hydroxide $(\mathrm{MH})[4,5]$ and aluminum hydroxide (ATH) [6], have been extensively utilized as halogen-free flame retardants. However, the usage of metal hydroxides will reduce the ductility of asphalt, which leads to the requirement of excessive metal hydroxides addition (at ca. 35 to $65 \mathrm{wt} \%$ ) in order to pass the flame retardancy tests [7] and hence renders the asphalt fragile and brittle [8].

Synergistic combinations are well-known allowing the reductions of flame retardant loading with fewer negative effects, where nanoclays have been reported to possess positive effects on the flame retardant properties of polymers [9] and show potential synergists with metal hydroxide flame retardants $[10,11]$. A small amount $(1-5 \mathrm{wt} \%)$ of nanoclays can significantly slow down the heat release rate of polymer combustion and improve the polymer mechanical properties, for example, tension, compression, bending, and fracture [12]. And the nanomodified asphalt may improve the rutting, crack, and fatigue resistance of asphalt mixtures [13, 14]. However, the flame retardant effect of montmorillonite on asphalts still has no consensus. Bonati et al. [15] proved that when ATH was coupled with organically modified montmorillonite (OMMT), a dramatic decrease of heat and smoke releases as generated by asphalt mixture combustion could be achieved, which was proposed due to the enhanced protective char layer that acts as an insulator and mass 
transport barrier. Wu et al. [16] reported that a $5 \mathrm{wt} \%$ OMMT could improve the LOI of asphalt from $19.8 \%$ to $23.6 \%$ and reduce the heat release rate of the asphalt combustion. However, Bourbigot et al. [17] reported an inconsistent result that a $5 \mathrm{wt} \%$ OMMT did not enhance the fire behavior of asphalt, but the peak heat release rate was even increased by $18 \%$. Furthermore, it has been well reported that the flame retardancy of nanocomposites are closely related to the degree of nanoclays dispersion in the matrix, where a good dispersion would always result in remark flame retardancy $[18,19]$. However, Barral et al. [20] have indicated that comparing to a mixture of ATH and modified sepiolite, the mixture of ATH and unmodified sepiolite that was with poor affinity could result in a relatively good fire performance. Accordingly, a detailed and more comprehensive study on the effects of montmorillonite and/or metal hydroxide addition on the ignitability and thermal stability of asphalt is still highly demanded with an aim to untangle the aforementioned debates.

In this paper, the limiting oxygen index (LOI), cone calorimeter, and TG-DSC test have been conducted to investigate the combustion characteristics of the asphalt with unmodified and modified montmorillonite, where the synergistic effects of montmorillonite and aluminium trihydrate were discussed. We expect that the work conducted herein could provide a scientific basis and reference for the selection of high performance and cost effective flame retardant for asphalt combustion.

\section{Experimental}

2.1. Materials. 70\# heavy traffic asphalt was obtained from BaoLi Asphalt Co., Ltd., in Jiangsu province, China. The flash point is $340^{\circ} \mathrm{C}$ and the ignition point is $375^{\circ} \mathrm{C}$.

Three different flame retardants were used: (1) aluminum hydroxide $(\mathrm{ATH})$, analytically pure with $d_{50}$ of $13.5 \mu \mathrm{m}$; (2) unmodified montmorillonite K-10 (MMT) with specific surface area at $240 \mathrm{~m}^{2} / \mathrm{g}$; (3) DK2 series organically modified montmorillonite (OMMT), industrial grade. The OMMT was purchased from Fenghong New Material Co., Ltd. (Zhejiang, China), which was modified with methyl tallow bis(2-hydroxyethyl) ammonium. The addition of ammonium can change the surface properties of montmorillonite from hydrophilic to lipophilic and improve the affinity of the montmorillonite and asphalt.

Melt blending method was used to prepare the flame retardant asphalt, where approximately $500 \mathrm{~mL}$ asphalt was loaded into a stainless steel can and heated up to $170 \pm 5^{\circ} \mathrm{C}$ by an electric furnace. Then, the mineral fillers (ATH, MMT, and OMMT) were added gradually, which were mixed by using a BME100LT high shear machine. The rotation speed was set as $5000 \mathrm{rpm}$ for $30 \mathrm{~min}$ to ensure the dispersion of mineral fillers, following by a lower speed of $500 \mathrm{rpm}$ for $15 \mathrm{~min}$ with an aim to expel the air bubbles.

2.2. Testing Methods. X-ray diffraction (XRD) technique was used to determine the dispersion of montmorillonite (MMT and OMMT) in modified asphalts. The XRD patterns were obtained using a Rigaku D/Max 2550 diffractometer with
$\mathrm{Cu} \mathrm{K} \alpha$ radiation $(\lambda=0.154 \mathrm{~nm})$ at $40 \mathrm{kV}$ and $100 \mathrm{~mA}$. The diffractograms were scanned in the $2 \theta$ range from $1^{\circ}$ to $30^{\circ}$.

Limiting oxygen index (LOI) is the minimal oxygen concentration that allows the sample to burn in a stable way. Samples with high LOI will need higher oxygen concentrations to ignite them. As such, an effective flame retardant would significantly increase the LOI of the asphalt. The LOI was determined according to an ASTM D 2863, which was performed by a HC-2 limiting oxygen index analyzer. Since the asphalt is subjected to melting and dripping while burning, glass fiber mat was used to support the asphalt during the test. Samples were prepared at 20/1 asphalt/glass fiber mat ratio by weight with dimensions of $120 \mathrm{~mm} \times 3 \mathrm{~mm}$ $\times 3 \mathrm{~mm}$. The test procedure was described in detail by Cong et al. [21].

Cone calorimeter was used to investigate the combustion characters of asphalt with mineral fillers, which is considered as a fitting laboratory test to describe the actual fire response of road pavement with asphalt [6]. During the test, samples were poured into a round cake with $70 \mathrm{~mm}$ diameter and $10 \mathrm{~mm}$ thickness, which were then exposed to a FTT 0007 cone calorimeter (FTT Company, UK) according to ISO5660 standard procedures under a heat flux of $50 \mathrm{~kW} / \mathrm{m}^{2}$. Different fire properties of the asphalts were evaluated, such as time to ignition (TTI), heat release rate (HRR), effective heat combustion (EHC), CO yield (COY), total heat release (THR), and total smoke release (TSR) (see Table 4).

Thermogravimetry analysis (TGA) was conducted to study the thermal properties of asphalts. The test was performed by a thermogravimetric analyzer (STA-409PC, NETZSCH, 6 Germany) under an air atmosphere with the gas flux of $20 \mathrm{~mL} / \mathrm{min}$. Approximately $10 \mathrm{mg}$ of the sample was placed in an aluminum oxide crucible with a cross-section area of $4.9 \times 10^{-4} \mathrm{~m}^{2}$. Samples were heated from $30^{\circ} \mathrm{C}$ to $850^{\circ} \mathrm{C}$ at a heating rate of $10^{\circ} \mathrm{C} / \mathrm{min}$.

\section{Results and Discussion}

3.1. Dispersion of Clay Particles in Montmorillonite Modified Asphalts. As reported, the flame retardancy of nanocomposites is closely related to the degree of nanoclays dispersion in the matrix, where the XRD techniques can be used to determine the dispersion of the layered clays in polymers [13]. When the asphalt chains are inserted into the gallery space between the silicate layers, the interlayer spacing of the clays $(d(001))$ would be widened. So according to the Bragg equation the diffraction angle $(2 \theta)$ of the $d(001)$ peak of XRD pattern would shift to a lower angle. When the layered clays are fully exfoliated, the individual silicate layers are no longer close enough to interact with each other and the $d(001)$ peak would disappear. Figure 1 shows the XRD patterns of the clays (MMT and OMMT) and the modified asphalts with $3 \mathrm{wt} \%$ OMMT or OMMT (called 3\% MMT and 3\% OMMT), respectively.

It is observed that the modified asphalt with $3 \mathrm{wt} \% \mathrm{MMT}$ shows a larger diffraction peak width than the original MMT, indicating that the inhomogeneity of interlayer spacing of the modified asphalt was increased and part of asphalt had entered into the clay gallery. Since the MMT losses its crystal 
TABLE 1: LOI value of asphalt with montmorillonites.

\begin{tabular}{lccccccc}
\hline Samples & Asphalt & 1\% MMT & 3\% MMT & 5\% MMT & 1\% OMMT & 3\% OMMT & 5\% OMMT \\
\hline LOI/\% & 19.8 & 20.1 & 20.4 & 20.6 & 19.9 & 20.2 & 20.3 \\
\hline
\end{tabular}

TABLE 2: Fire properties of asphalt with montmorillonites obtained from cone calorimeter.

\begin{tabular}{lccccccc}
\hline \multirow{2}{*}{ Samples } & \multirow{2}{*}{ TTI/s } & \multicolumn{2}{c}{$\mathrm{HRR} /\left(\mathrm{kW} \cdot \mathrm{m}^{-2}\right)$} & \multirow{2}{*}{$\mathrm{EHC} /\left(\mathrm{MJ} \cdot \mathrm{kg}^{-1}\right)$} & COY $/\left(\mathrm{kg} \cdot \mathrm{kg}^{-1}\right)$ & \multirow{2}{*}{$\mathrm{THR} /\left(\mathrm{MJ} \cdot \mathrm{m}^{-2}\right)$} & \multirow{2}{*}{$\mathrm{TSR} /\left(\mathrm{m}^{2} \cdot \mathrm{m}^{-2}\right)$} \\
\hline Base asphalt & 23 & 289.6 & $581.2 / 195$ & 29.41 & 0.0729 & 165.1 & 9515 \\
3\% MMT & 43 & 245.1 & $500.7 / 155$ & 31.26 & 0.0782 & 185.1 & 10503 \\
3\% OMMT & 22 & 259.8 & $498.1 / 130$ & 29.81 & 0.0744 & 188.3 & 10692 \\
\hline
\end{tabular}

*TTI: time to ignition, HRR: heat release rate, EHC: effective heat combustion, COY: CO yield, THR: total heat release, and TSR: total smoke release.

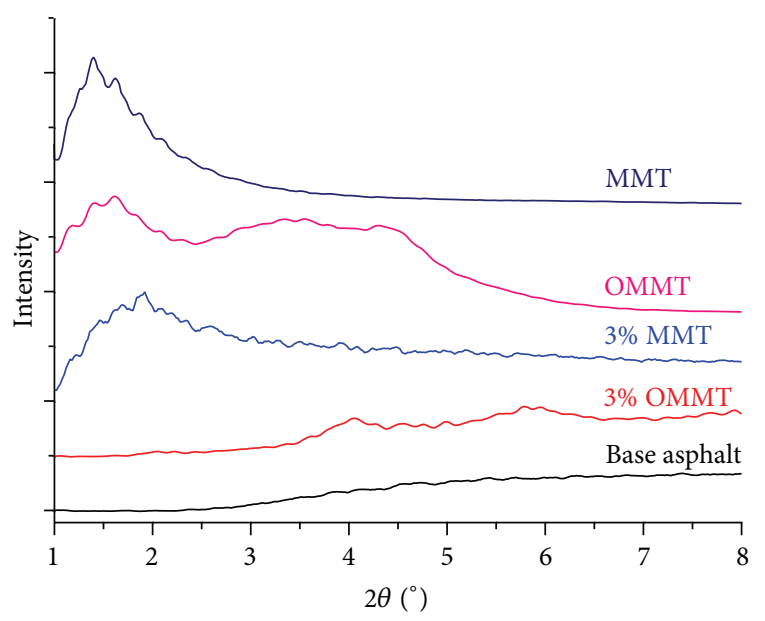

Figure 1: X-ray diffraction patterns of montmorillonites and asphalts.

water during the mixing process, the interlayer spacing of the MMT would be slightly reduced after mixing. Consequently, the modified asphalt with $3 \mathrm{wt} \%$ MMT would possess an immiscible/intercalated structure.

The OMMT powder shows a $5.45 \mathrm{~nm} d$-spacing, while the modified asphalt with $3 \mathrm{wt} \%$ OMMT shows no significant diffraction peak. This indicates that the modified OMMT had resulted in an exfoliated structure in the asphalt. This structure was generally achieved due to the quaternary ammonium compound that works as an organic intermediate between the hydrophobic asphalt and hydrophilic montmorillonite. As such, most of OMMT layers would be peeled off during the mixing process, forming a more uniform dispersion structure.

\subsection{Flame Retardancy of Montmorillonite Modified Asphalts.} The limiting oxygen index (LOI) technique can provide a quantitative measurement on the flammability of polymers. Generally, polymers with LOI $<21 \%$ belong to flammable materials, where those with $21 \%<\mathrm{LOI}<27 \%$ are conventionally classified as "slow burning" materials and LOI $>27 \%$ as "self-extinguishing" materials [22].

It can be seen that the base asphalt has the LOI to be equal to $19.8 \%$. Since the oxygen volumetric content in atmosphere is approximately $21 \%$, materials characterized by LOI smaller than $21 \%$ can be ignited by an open fire and burn stably in air. From Table 1, we can observe that the limited oxygen index of asphalt was increased slightly with the contents of MMT or OMMT. The LOI of asphalts with MMT were larger than that with OMMT of the same content. However, the induced LOI rise of MMT and OMMT were not significant, leading to that the modified asphalt still belongs to the flammable materials. According to the GB/T 29051-2012, the limited oxygen index of tunnel asphalt pavement should be greater than $23 \%$. Therefore, only adding montmorillonite cannot meet the LOI standard for the asphalt materials.

However, it should be noted that although the LOI test is effective as a screening tool for flame retardants, its test condition cannot fully represent a real fire scenario. In order to further determine the impact of montmorillonite on the combustion characteristics and fire hazard of asphalt under a high heat flux condition, cone calorimeter test was then used to analyze the combustion characteristics of the asphalt under an external thermal radiant flux of $50 \mathrm{~kW} / \mathrm{m}^{2}$. The results are present in Table 2.

It can be seen that the time to ignition (TTI) was increased from 23 to $43 \mathrm{~s}$ upon the addition of a $3 \mathrm{wt} \%$ MMT. This is due to the fact that the dispersed clays in the asphalt can prevent the permeation of oxygen, so that the chain oxidation reaction of asphalt could be inhibited as well as the ignition could be retarded. In Barral et al's research [20], a significant delay of the ignition time was also observed when a $4 \mathrm{wt} \%$ unmodified sepiolite (another layered silicate) was added. However, after adding $3 \mathrm{wt} \%$ OMMT, the ignition time of asphalt was substantially constant. This is because of the fact that the organic modifier (alkyl quaternary ammonium) has a low thermal stability, which would increase the flammability of the asphalt.

Heat release rate is the critical factor in predicting the contribution of a burning material to the growth of a fire. From Figure 2, the heat release rate was increased rapidly after the base asphalt was ignited, which reached a maximum value $\left(>500 \mathrm{~kW} \cdot \mathrm{m}^{-2}\right)$ within $5 \mathrm{~min}$. After adding $3 \mathrm{wt} \% \mathrm{MMT}$ or OMMT, the heat release rates were decreased by $13.9 \%$ or $14.3 \%$, respectively. The decomposition products of the montmorillonite migrate to the surface in high temperature range, leading to the reduction of small amounts of carbon 
TABLE 3: LOI value of asphalt with ATH and montmorillonite.

\begin{tabular}{lcccccc}
\hline Samples & $5 \%$ ATH & $10 \%$ ATH & $17.5 \%$ ATH & $25 \%$ ATH & $3 \%$ MMT + 25\% ATH & $3 \%$ OMMT + 25\% ATH \\
\hline LOI $/ \%$ & 21.0 & 22.7 & 24.2 & 26.9 & 28.8 & 26.6 \\
\hline
\end{tabular}

TABLE 4: Fire properties of asphalt with ATH and montmorillonite obtained from cone calorimeter.

\begin{tabular}{|c|c|c|c|c|c|c|c|}
\hline \multirow{2}{*}{ Samples } & \multirow{2}{*}{$\mathrm{TTI} / \mathrm{s}$} & \multicolumn{2}{|c|}{$\mathrm{HRR} /\left(\mathrm{kW} \cdot \mathrm{m}^{-2}\right)$} & \multirow{2}{*}{$\mathrm{EHC} /\left(\mathrm{MJ} \cdot \mathrm{kg}^{-1}\right)$} & \multirow{2}{*}{$\mathrm{COY} /\left(\mathrm{kg} \cdot \mathrm{kg}^{-1}\right)$} & \multirow{2}{*}{$\mathrm{THR} /\left(\mathrm{MJ} \cdot \mathrm{m}^{-2}\right)$} & \multirow{2}{*}{$\mathrm{TSR} /\left(\mathrm{m}^{2} \cdot \mathrm{m}^{-2}\right)$} \\
\hline & & Average & Peak/Time & & & & \\
\hline $25 \%$ ATH & 34 & 180.6 & $450.0 / 135$ & 27.05 & 0.0557 & 186.1 & 8984 \\
\hline $25 \% \mathrm{ATH}+3 \% \mathrm{MMT}$ & 43 & 161.6 & $393.2 / 120$ & 30.37 & 0.0631 & 207.6 & 9668 \\
\hline $25 \% \mathrm{ATH}+3 \% \mathrm{OMMT}$ & 31 & 139.0 & $247.5 / 60$ & 31.02 & 0.0647 & 175.2 & 8037 \\
\hline
\end{tabular}

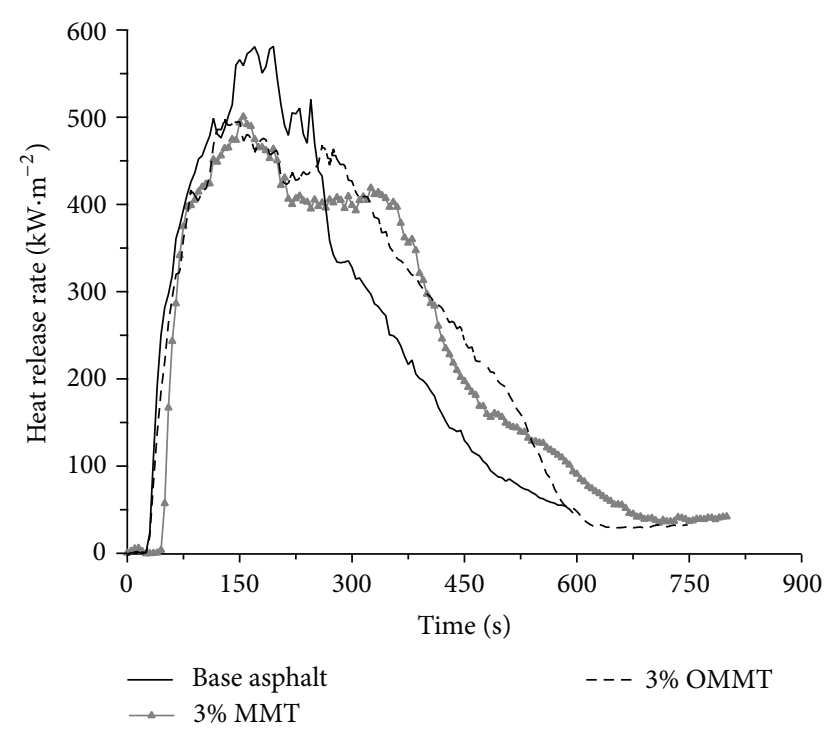

FIGURE 2: Heat release rate curves for asphalt with montmorillonites.

atoms [23], and the formation of a barrier layer is shown in Figure 3. The formed barrier layer would reduce the heat and mass transfer between the asphalt surface and external environment [7], resulting in the development of fire being limited. In addition as shown in Table 2, the addition of montmorillonite (MMT and OMMT) had no obvious effect on the effective heat combustion and $\mathrm{CO}$ yield for the asphalt combustion.

According to the aforementioned results, it can be concluded that addition of a small amount of montmorillonite (MMT and OMMT) cannot significantly increase the limiting oxygen index of the asphalt, but the ignition time in cone calorimeter test could be improved from 23 to $43 \mathrm{~s}$ after the $3 \mathrm{wt} \% \mathrm{MMT}$ was added. Adding montmorillonite (MMT and OMMT) also showed a relatively obvious decline of the heat release rate. Clearly, the results of LOI test and cone calorimeter test were not well unified. The asphalt is a polymer whose melting temperature is lower than its pyrolysis temperature. At a low heat flux (e.g., LOI test), the heating rate is relatively low, which has led to the fact that the melting would precede the volatilization and ignition. Furthermore, since the asphalt can flow or drip, it would further remove the heat from the surface. However, adding montmorillonite will increase the viscosity of the asphalt [14], thereby inhibiting the dripping of asphalt and promoting the combustion. This effect would offset the barrier effect of the montmorillonite partially, leading to the increase of LOI being limited. On the other hand, at a higher heat flux (e.g., cone calorimeter test), the temperature was increased rapidly and the ignition may occur before the surface is heated to a sufficient depth for the melted material to flow [24]. Accordingly, the montmorillonite might promote the formation of the barrier layer, so the thermal stability of the montmorillonite modified asphalt was improved.

3.3. Flame Retardancy of Montmorillonite and Aluminium Trihydrate. As shown in Section 2.2, the flame retardant effect of the montmorillonite (MMT and OMMT) mainly focuses on reducing the heat release rate of the asphalt combustion, where adding montmorillonite had shown no significant improvement on asphalt's flammability and CO yield. Since aluminum hydroxide had shown flame retardant and smoke suppressant properties, it was then used with montmorillonite to synergistically reduce the flammability and heat release of the asphalt.

Table 3 presents the LOI value of the asphalt with different contents of ATH and montmorillonite (MMT and OMMT). As the ATH content was increased from $0 \%$ to $25 \mathrm{wt} \%$, the LOI was rapidly increased from $19.8 \%$ to $26.9 \%$. It is noted that the change of ATH content has an obvious effect on the flammability of the asphalt. Synergistically adding $3 \mathrm{wt} \%$ OMMT with $25 \mathrm{wt} \%$ ATH, the LOI had declined to $26.6 \%$, whilst adding $3 \mathrm{wt} \%$ MMT with $25 \mathrm{wt} \%$ ATH, the LOI had further increased to $28.8 \%$ (i.e., yielding a self-extinguishing material for asphalt). This increase was much higher than that added $3 \mathrm{wt} \%$ MMT in the base asphalt (from $19.8 \%$ to $20.4 \%$ ).

Cone calorimeter test was used to analyze the combustion characteristics of the modified asphalt with ATH and montmorillonite under an external thermal radiant flux of $50 \mathrm{~kW} / \mathrm{m}^{2}$. The ignition of $25 \%$ ATH occurred at $34 \mathrm{~s}$, which was later than that of base asphalt (at $23 \mathrm{~s}$ ). The ignition time was further increased to $43 \mathrm{~s}$ after adding $3 \mathrm{wt} \%$ MMT in $25 \%$ ATH but was decreased after adding $3 \mathrm{wt} \%$ OMMT. This was similar to that of adding montmorillonite in the base asphalt. It is well known that about $90 \%$ of fire deaths are the result of too much toxic smoke, where the carbon monoxide is always the primary one [25]. As such, the reduction of smoke and 


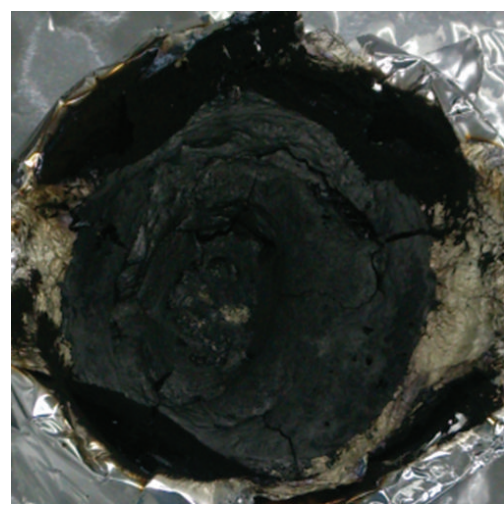

(a)

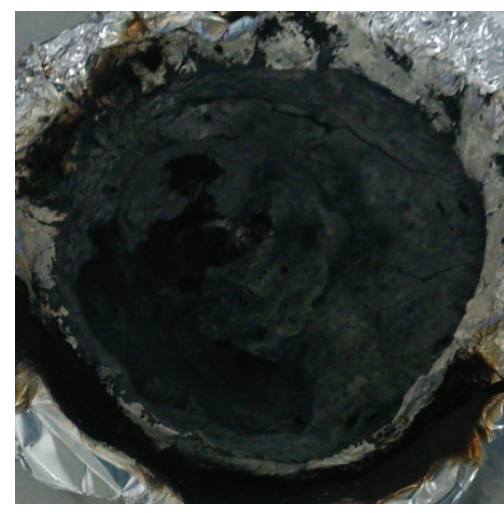

(b)

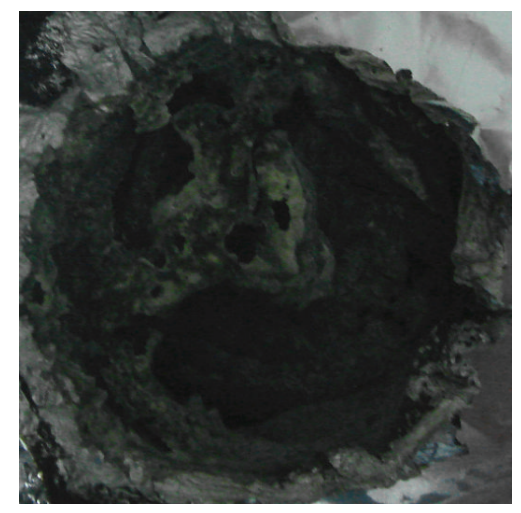

(c)

Figure 3: Cone residues of asphalt: (a) base asphalt; (b) 3\% OMMT; (c) 3\% MMT.

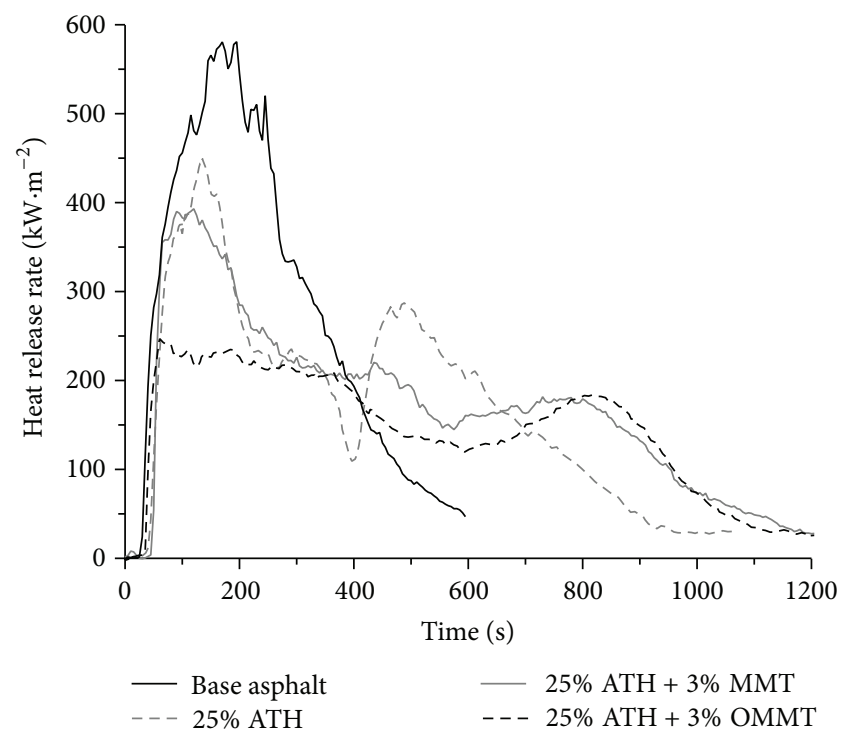

FIGURE 4: Heat release rate curves for asphalt with montmorillonite and ATH.

CO release during the asphalt combustion would be very beneficial for its practical application.

As shown in Figure 4, there were two main peaks in the heat release curve for adding $25 \mathrm{wt} \%$ ATH. The first peak was much lower than that of base asphalt. This was owed to the endothermic reaction of the ATH decomposition, which formed $\mathrm{Al}_{2} \mathrm{O}_{3}$ barrier layer that decreased the heat and mass transfer between the flame and material. As the combustion proceeded, the barrier layer structure was destroyed, which led to an evolution of the flammable volatile and the combustion of unburned asphalt. The second heat release peak then appeared. The addition of $25 \mathrm{wt} \%$ ATH had yielded a $37.6 \%$ reduction of the average heat release rate compared to the base asphalt, which had significantly increased the burnout time.

The incorporation in asphalt of $25 \mathrm{wt} \% \mathrm{ATH}+3 \mathrm{wt} \%$ MMT and $25 \mathrm{wt} \%$ ATH $+3 \mathrm{wt} \%$ OMMT had decreased the average heat release rates by $44.2 \%$ and $52.0 \%$ to base asphalt, respectively. Additional $3 \mathrm{wt} \% \mathrm{MMT}$ and $3 \mathrm{wt} \%$ OMMT even yielded $10.5 \%$ and $26.7 \%$ reduction of average HRR compared to the $25 \%$ ATH. In particular, when the OMMT was added, the shape of the HHR curve shows a plateau-like behavior. This behavior was typical for the char- or residue-forming materials [24]. The peak heat release rate was observed to be decreased by $45.0 \%$ compared to $25 \%$ ATH. Obviously, the OMMT and ATH had both shown excellent synergistic flame retardant effect on reducing the heat release rate of the asphalt combustion. The formation of an inert barrier layer was probably the most important factor for flame retardant as it might keep the heat and oxygen out of the asphalt matrix. Furthermore, the additional incorporation of $3 \mathrm{wt} \%$ OMMT had resulted in the formation of a denser barrier layer with less crack (Figure 5(b)). This could be due to the good dispersion of the OMMT, which stripped to form a network structure in the asphalt matrix. Such network structure would increase the asphalt's viscosity, leading to a more "solid-like" behavior for the asphalt during the combustion, which hence resulted in the formation of barrier.

The silicate layer of the montmorillonite not only strengthens the char, making it more resistant to ablation, but also plays an active role in the formation of the char. The mass loss curves of Figure 6 show that the additions of montmorillonite (MMT and OMMT) had yielded an increase of the residue mass. The increase is about $1 \%-2 \%$, which is mainly owing to the unreacted montmorillonite. When the montmorillonite was coordinated with the ATH, such increase would be more significant $(8 \%-10 \%)$. The increase is much more than the ratio of montmorillonite (3\%). This is mainly because the montmorillonite makes the barrier layer denser, part of asphalt could not burn completely, and the mass of residue increases.

In addition, it is noteworthy to mention that adding the ATH did not decrease the effective heat of the asphalt combustion, the total heat release, and the total smoke release significantly. This implied that the reaction between the ATH and asphalt was only a physical blending process, where the chemical interactions did not play a major role during the process. 


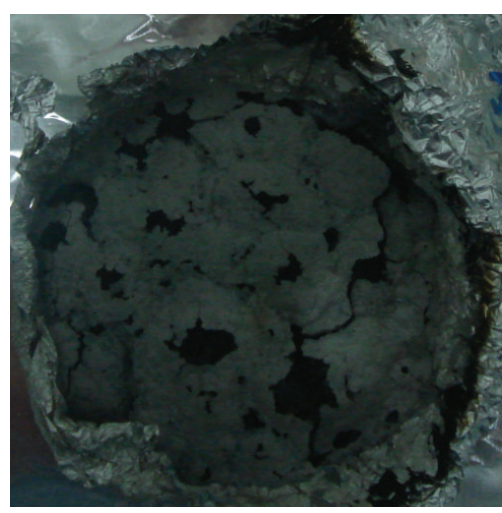

(a)

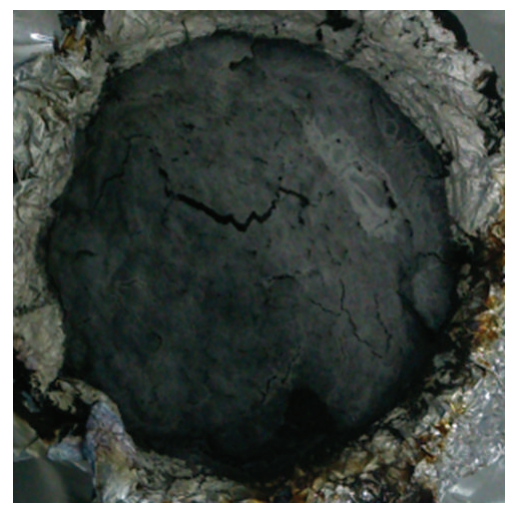

(b)

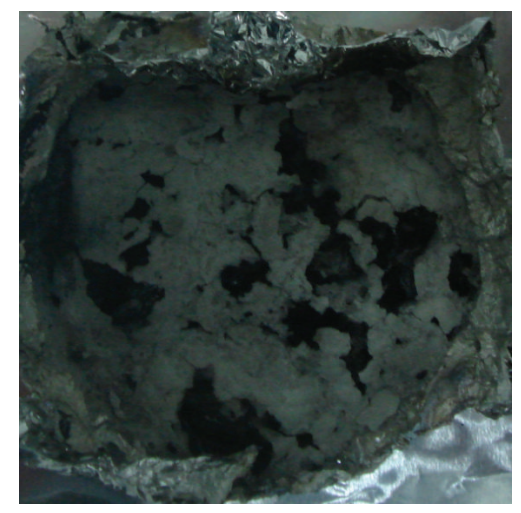

(c)

FIGURE 5: Cone residues of asphalt: (a) 25\% ATH; (b) 25\% ATH + 3\% OMMT; (c) 25\% ATH + 3\% MMT.

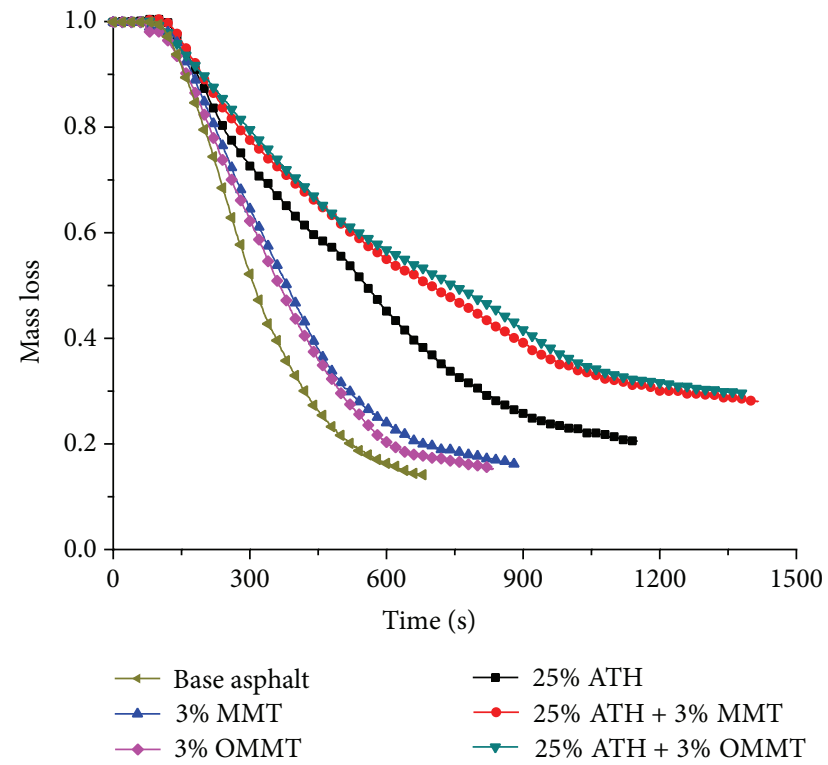

FIGURE 6: Mass loss curves for asphalt with montmorillonite and ATH.

3.4. Thermal Analysis. TGA experiments were performed to examine the decomposition behavior of the flame retardants. The mass loss (TG) curves are shown in Figure 7, which reflects the relationship between the mass loss and temperature. It was observed that there is an obvious mass loss rate peak in the DTG curve for both the MMT and OMMT addition at the temperature range of $70-100^{\circ} \mathrm{C}$. This peak was known to correspond to the loss of crystal water. Since this temperature was much lower than the mixing temperature of the asphalt mixture, the process played no effect on the flame retardancy for the asphalt. As the temperature rose, the ATH began to decompose at about $300^{\circ} \mathrm{C}$, whereas the ammonium in the OMMT was ignited. Since this temperature was lower than the ignition point of the base asphalt, the OMMT could not reduce the ignitability of the asphalt, which had led to the ignition time being shortened during the cone calorimeter tests.

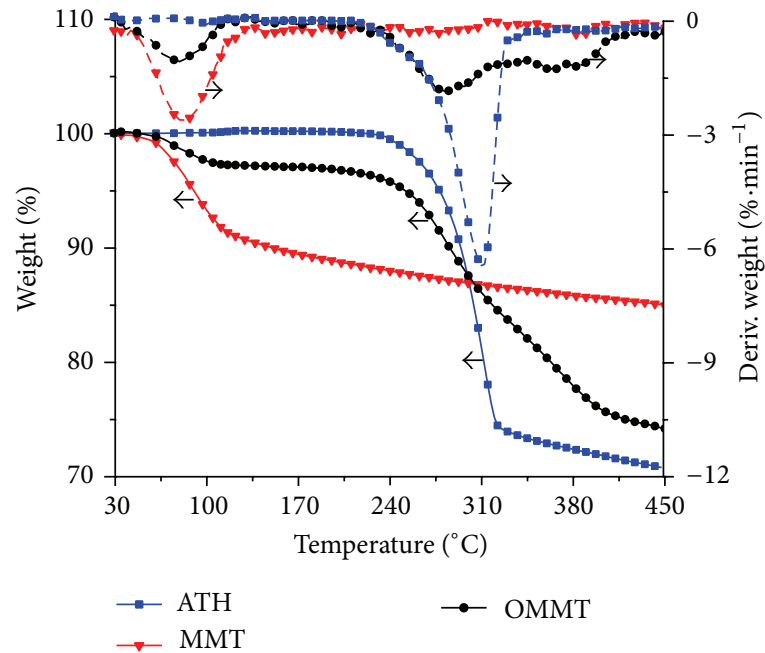

FIGURE 7: Thermal gravimetric analysis of fillers.

The TGA experiments were also performed to test the combustion behavior of the asphalts with different flame retardants (see Figure 8). DTG curves of the asphalts after or before adding montmorillonite (MMT and OMMT) both indicated that the combustion process could be mainly divided into two stages. The first peak was present in the initial combustion stage of the asphalt combustion, which was owing to the release of oil content and resin [26]. At this stage, the addition of $3 \mathrm{wt} \%$ MMT and $3 \mathrm{wt} \%$ OMMT could both result in the peak shifting to lower temperature range. This implied that the montmorillonite could not significantly reduce the ignition of asphalt. However, the mass loss at this stage was reduced from $66.5 \%$ to $61.3 \%$ or $62.4 \%$ for $3 \%$ MMT or 3\% OMMT, respectively. This is because of the fact that the montmorillonite had increased the viscosity of asphalt [13] and suppresses the release of flammable volatiles. This may lead to a longer reaction time, where more active ingredients cannot diffuse out at the lower temperature but convert themselves into more stable products, for example, asphaltenes. As such, the mass loss of 3\% MMT and $3 \%$ 


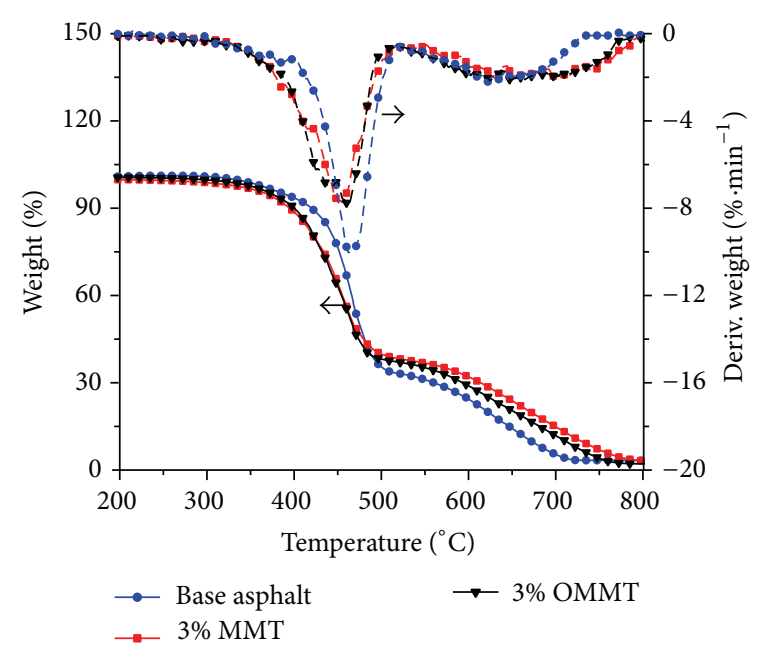

FIGURE 8: Thermal gravimetric analysis of asphalt with nanoclays.

OMMT became less than that of base asphalt at stage one. The second peak corresponded to the stage of asphaltenes combustion [26]. After montmorillonite was added, the temperature range of this stage was postponed, where the burnout temperature was raised by more than $50^{\circ} \mathrm{C}$, leading to the reduction on heat release and fire expansion.

Compared to montmorillonite addition alone, the DTG curve of asphalt combustion had three main peaks after adding ATH. As shown in Figure 9, the first peak occurred at about $300^{\circ} \mathrm{C}$, which corresponded to the decomposition of ATH and the combustion of ammonium in OMMT. There were significant amounts of heats being absorbed from the asphalt due to the ATH decomposition, which would cause a falling of the temperature in the combustion zone, leading to the retarding on the reaction. The second peak corresponded to the first stage of asphalt combustion. The mass loss and maximum mass loss rate were reduced compared to the base asphalt, which was owning to the barrier effect of the residue of ATH decomposition. When ATH was combined with montmorillonite (MMT or OMMT), the mass loss at the stage two would be further reduced from $53.7 \%$ to $49.4 \%$ or $48.4 \%$, respectively. This led to the increase in the formation of asphaltenes and the prolongation of asphaltenes combustion, which was similar to that of adding montmorillonite alone during asphalt combustion.

\section{Conclusions}

(1) Adding a small amount of montmorillonite (MMT and OMMT) cannot significantly increase the oxygen index of asphalt. However, it could promote the formation of barrier layer during asphalt combustion and suppress the release of flammable volatiles. Consequently, the heat release rate would be reduced and the burnout time of asphalt would be postponed.

(2) The addition of montmorillonite (MMT and OMMT) and aluminum hydroxide had shown a synergistic

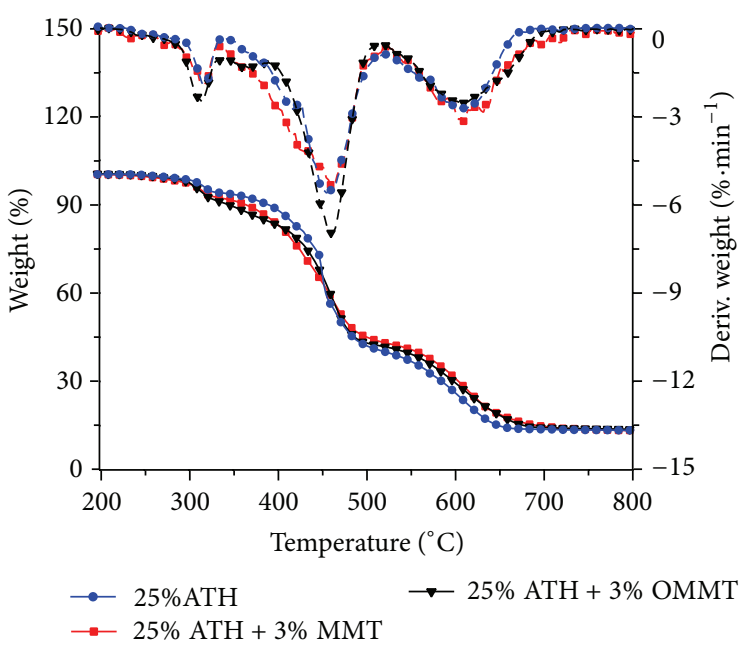

FIGURE 9: Thermal gravimetric analysis of asphalt with nanoclay and ATH.

effect on flame retardancy. The addition of montmorillonite and aluminum hydroxide further reduced the heat release rate. After further addition of OMMT, the heat release rate was significantly decreased. This could be attributed to the formation of barrier layer, which acted as a mass and heat barrier to protect the underlying material from further burning.

(3) Adding a small amount of unmodified montmorillonite could increase the ignition time of asphalt, while adding OMMT asphalt cannot. This was owing to the flammability of the ammonium in the modified montmorillonite.

To sum, it can be concluded that the OMMT can reduce the heat release rate of the asphalt and has a remark synergistic effect on the flame retardancy when it is used together with aluminum hydroxide, showing a promising flame retardant for asphalt combustion. However, since the traditional alkyl ammonium modifier is generally flammable, it is necessary to synthesis an organic modifier with fire-retardant properties in the future.

\section{Conflict of Interests}

The authors declare that there is no conflict of interests regarding the publication of this paper.

\section{Acknowledgments}

This work is supported by the Zhejiang Provincial Natural Science Foundation of China (no. LY14E080014) and the National Natural Science Foundation of China (no. 5140080784). The authors would like to thank Dr. Xiaole Weng at College of Environmental \& Resource Sciences of Zhejiang University for his help in this paper. 


\section{References}

[1] T. Xu, X. Huang, and Y. Zhao, "Investigation into the properties of asphalt mixtures containing magnesium hydroxide flame retardant," Fire Safety Journal, vol. 46, no. 6, pp. 330-334, 2011.

[2] R. Carvel and J. Torero, "The contribution of asphalt road surfaces to fire risk in tunnel fire, in the contribution of asphalt road surfaces to fire risk in tunnel fires: preliminary findings," in Proceedings of the International Conference on Risk and Fire Engineering for Tunnels, Stations and Linked Underground Spaces, pp. 19-20, Hong Kong, 2006.

[3] K. Wu, K. Zhu, Z. Huang, J. Wang, Q. Yang, and P. Liang, "Research on the combustion mechanism of asphalt and the composition of harmful gas based on infrared spectral analysis," Spectroscopy and Spectral Analysis, vol. 32, no. 8, pp. 2089-2094, 2012.

[4] T. Xu and X. Huang, "A TG-FTIR investigation into smoke suppression mechanism of magnesium hydroxide in asphalt combustion process," Journal of Analytical and Applied Pyrolysis, vol. 87, no. 2, pp. 217-223, 2010.

[5] T. Xu and X. Huang, "Combustion properties and multistage kinetics models of asphalt binder filled with flame retardant," Combustion Science and Technology, vol. 183, no. 10, pp. 10271038, 2011.

[6] A. Bonati, F. Merusi, G. Polacco, S. Filippi, and F. Giuliani, "Ignitability and thermal stability of asphalt binders and mastics for flexible pavements in highway tunnels," Construction and Building Materials, vol. 37, pp. 660-668, 2012.

[7] A. B. Morgan, "Flame retarded polymer layered silicate nanocomposites: a review of commercial and open literature systems," Polymers for Advanced Technologies, vol. 17, no. 4, pp. 206-217, 2006.

[8] R. M. Recasens, A. Martínez, F. P. Jiménez, and H. Bianchetto, "Effect of filler on the aging potential of asphalt mixtures," Transportation Research Record, vol. 1901, no. 1, pp. 10-17, 2005.

[9] T. Kashiwagi, F. Du, J. F. Douglas, K. I. Winey, R. H. Harris Jr., and J. R. Shields, "Nanoparticle networks reduce the flammability of polymer nanocomposites," Nature Materials, vol. 4, no. 12, pp. 928-933, 2005.

[10] S. Bourbigot and S. Duquesne, "Fire retardant polymers: recent developments and opportunities," Journal of Materials Chemistry, vol. 17, no. 22, pp. 2283-2300, 2007.

[11] G. Beyer, "Flame retardancy of nanocomposites based on organoclays and carbon nanotubes with aluminum trihydrate," Polymers for Advanced Technologies, vol. 17, no. 4, pp. 218-225, 2006.

[12] M. Alexandre and P. Dubois, "Polymer-layered silicate nanocomposites: preparation, properties and uses of a new class of materials," Materials Science and Engineering R: Reports, vol. 28, no. 1, pp. 1-63, 2000.

[13] Z. You, J. Mills-Beale, J. M. Foley et al., "Nanoclay-modified asphalt materials: preparation and characterization," Construction and Building Materials, vol. 25, no. 2, pp. 1072-1078, 2011.

[14] J. Yu, X. Zeng, S. Wu, L. Wang, and G. Liu, "Preparation and properties of montmorillonite modified asphalts," Materials Science and Engineering A, vol. 447, no. 1-2, pp. 233-238, 2007.

[15] A. Bonati, F. Merusi, G. Bochicchio et al., "Effect of nanoclay and conventional flame retardants on asphalt mixtures fire reaction," Construction and Building Materials, vol. 47, pp. 9901000, 2013.
[16] S. Wu, Y. Zhang, and J. Wang, "A novel potential flameretarded bitumen nanoclay modified bitumen," Road Materials and Pavement Design, vol. 10, supplement 1, pp. 115-128, 2009.

[17] S. Bourbigot, O. Cerin, S. Duquesne, and N. Clavel, "Flame retardancy of bitumen: a calorimetry study," Journal of Fire Sciences, vol. 31, no. 2, pp. 112-130, 2013.

[18] J. W. Gilman, T. Kashiwagi, A. B. Morgan et al., Flammability of Polymer Clay Nanocomposites Consortium: Year One Annual Report, US Department of Commerce, Technology Administration, National Institute of Standards and Technology, 2000.

[19] M.-A. Paul, M. Alexandre, P. Degée, C. Henrist, A. Rulmont, and P. Dubois, "New nanocomposite materials based on plasticized poly (L-lactide) and organo-modified montmorillonites: thermal and morphological study," Polymer, vol. 44, no. 2, pp. 443-450, 2003.

[20] M. Barral, P. Garmendia, M. E. Muñoz et al., "Novel bituminous mastics for pavements with improved fire performance," Construction and Building Materials, vol. 30, pp. 650-656, 2012.

[21] P. Cong, S. Chen, J. Yu, and S. Wu, "Effects of aging on the properties of modified asphalt binder with flame retardants," Construction and Building Materials, vol. 24, no. 12, pp. 25542558,2010

[22] M. Burns, U. Wagenknecht, B. Kretzschmar, and W. W. Focke, "Effect of hydrated fillers and red phosphorus on the limiting oxygen index of poly(ethylene-co-vinyl actate)-poly(vinyl butyral) and low density polyethylene-poly(ethylene-co-vinyl alcohol) blends," Journal of Vinyl and Additive Technology, vol. 14, no. 3, pp. 113-119, 2008.

[23] H. Ma, P. Song, and Z. Fang, "Flame retarded polymer nanocomposites: development, trend and future perspective," Science China Chemistry, vol. 54, no. 2, pp. 302-313, 2011.

[24] A. B. Morgan and C. A. Wilkie, Flame Retardant Polymer Nanocomposites, Wiley-Interscience, 2007.

[25] K. M. Butler and G. W. Mulholland, "Generation and transport of smoke components," Fire Technology, vol. 40, no. 2, pp. 149176, 2004.

[26] W. Ke, K. Zhu, J. Han, J. Wang, Z. Huang, and P. Liang, “Nonisothermal kinetics of styrene-butadiene-styrene asphalt combustion," Chinese Physics B, vol. 22, no. 6, Article ID 068801, 2013. 

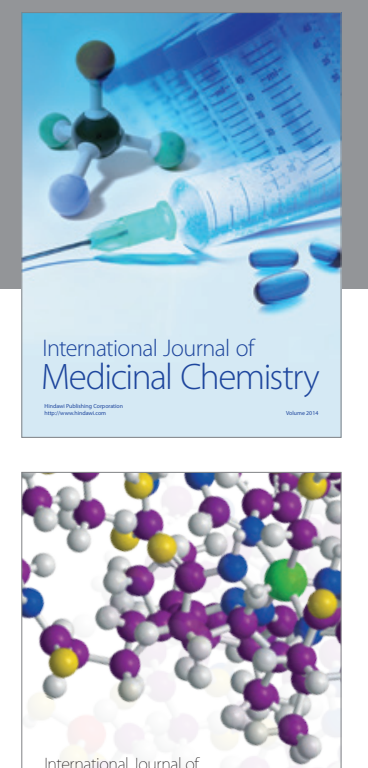

\section{Carbohydrate} Chemistry

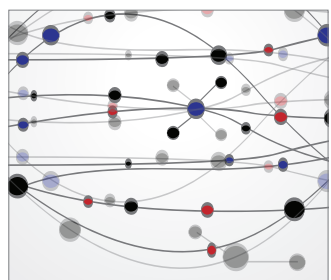

The Scientific World Journal
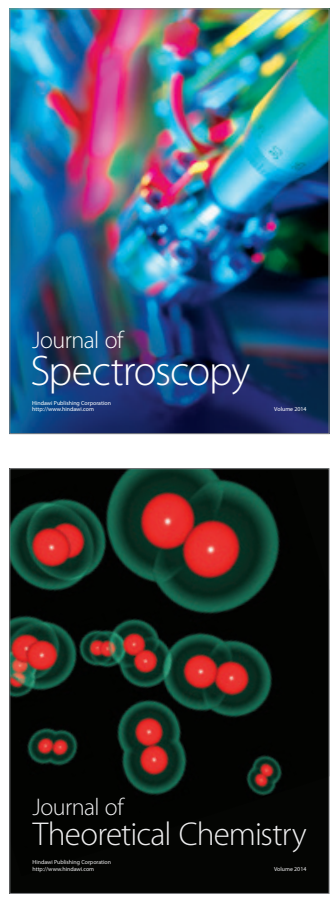
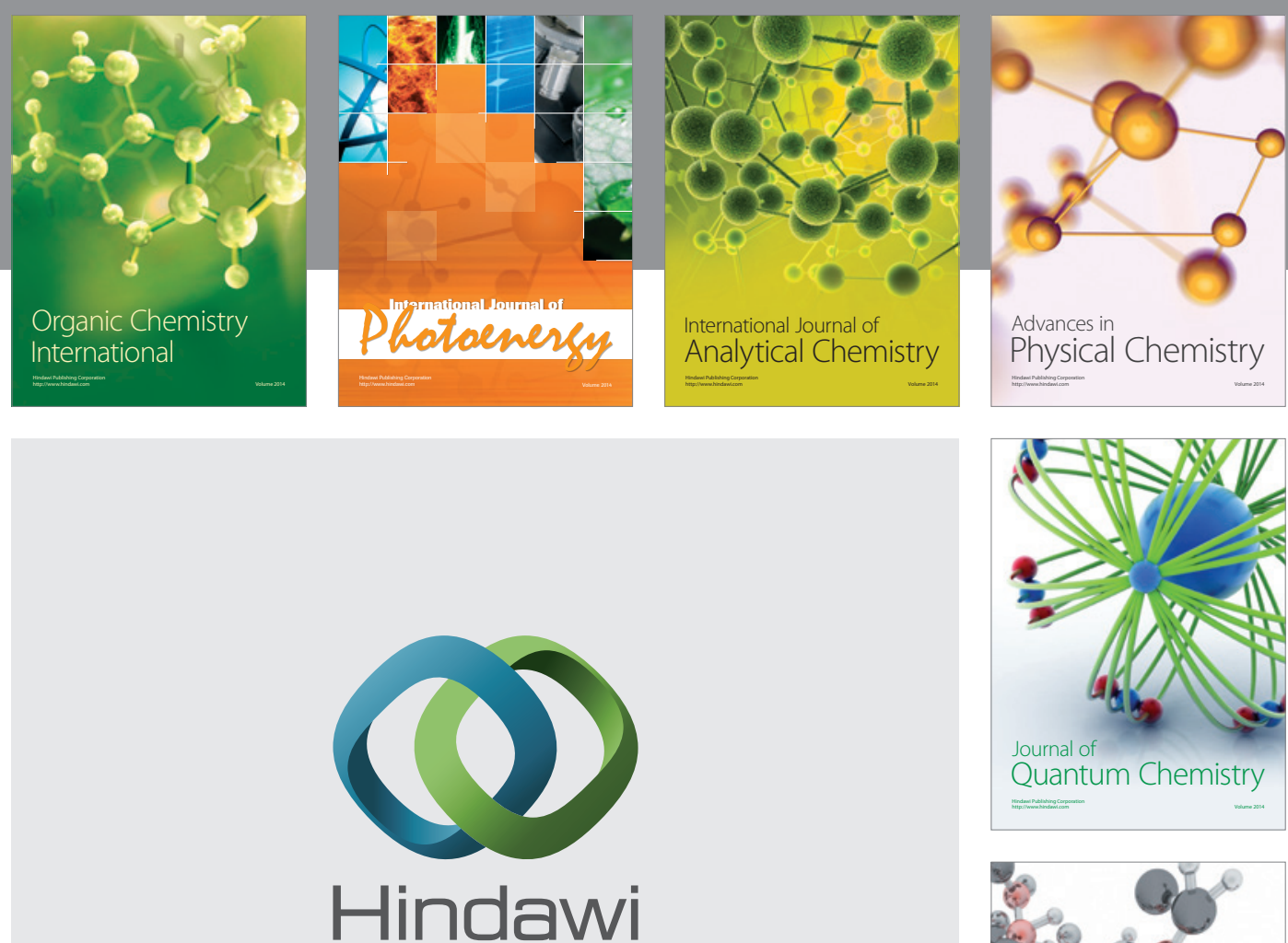

Submit your manuscripts at

http://www.hindawi.com

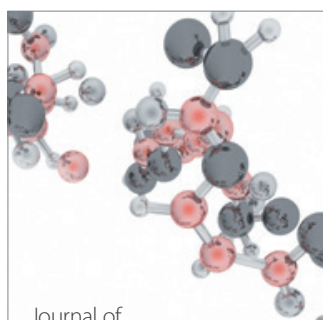

Analytical Methods

in Chemistry

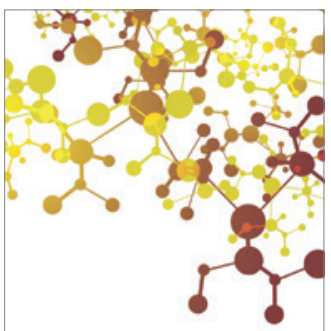

Journal of

Applied Chemistry

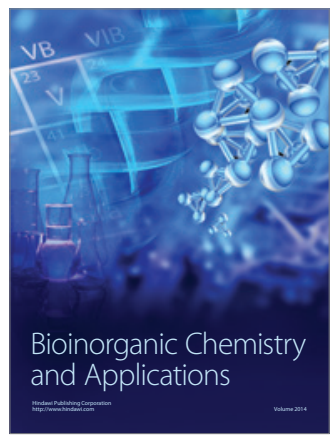

Inorganic Chemistry
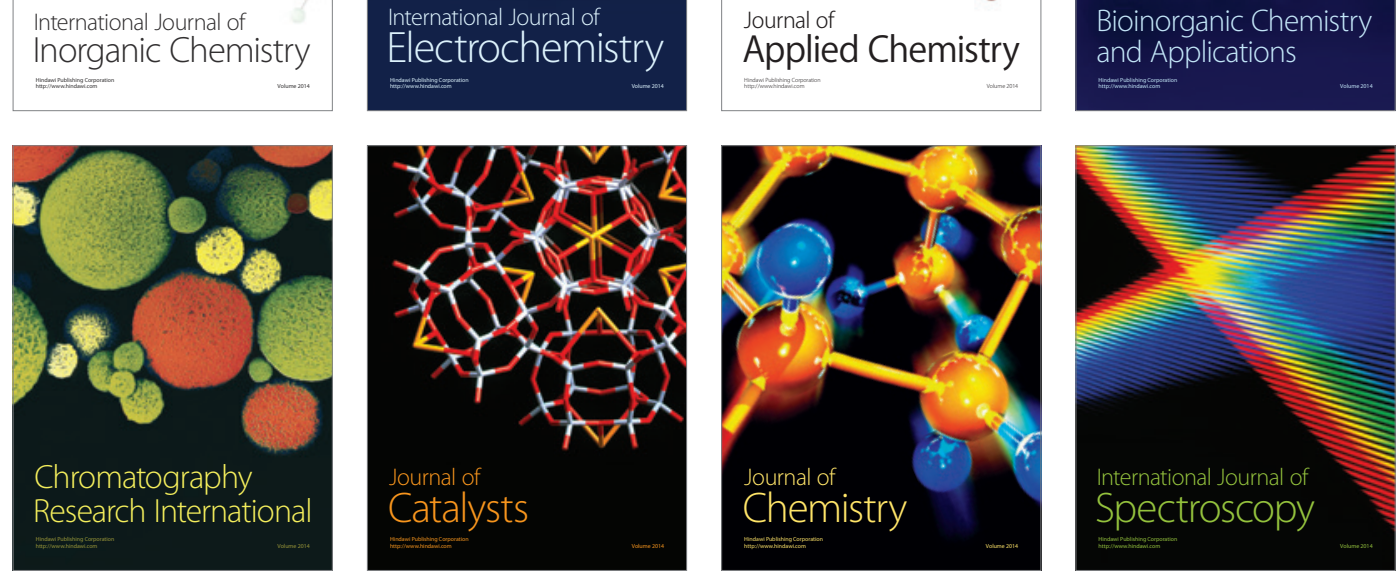